\title{
Is Routine Screening for TORCH Infection in Antenatal Women with Bad Obstetric History Worthwhile!
}

\section{Fatima $S^{*}$ \\ Department of Microbiology, Ayaan institute of medical sciences, India}

*Corresponding author: Sarwat Fatima, Department of Microbiology, Ayaan institute of medical sciences, Kanamamidi, Moinabad, Telangana state, India, Tel: +919701521370; Email: sarwatfatima73@gmail.com

\section{Review Article \\ Volume 1 Issue 2}

Received Date: September 03, 2019

Published Date: September 17, 2019

DOI: $10.23880 /$ aii-16000105

\section{Abstract}

Recent published data on seroprevalence and incidence of TORCH infection in pregnant women from developing countries shows a highly variable picture. So, in this scenario is routine TORCH screening of all bad obstetric history cases $[\mathrm{BOH}]$ worth? The topic is highly debatable. There are no strict local guidelines regulating its use. However, some developed nations have brought into practise mandatory infectious disease screening procedures during pregnancy like one by ACOG, HSE Ireland, NHS England and FOGSI which are really helpful in disease control and prevention. Problems arises when no guidelines exist or when they are not adhered to for diagnosis and management of the same. Fallacies are noted in the test request, timing, method and type of specimen used for testing and interpretation of test results. This review article intends to through light and brings out important facts associated with TORCH testing which will be of help to laboratory specialist and clinicians. And hopes in future will reduce the number of undue investigations and extra financial burden to the patient and his family when affordability is a big concern.

Keyword: TORCH Screening; Seroprevalence; Bad Obstetric History; Middle and low-income countries

Abbreviations: ACOG: American College of Obstetrics \& Gynaecology; HSE: Health Services Executive; FOGSI: Fe deration for Gynaecology and Obstetrics Society of India; NHS UK: National Health Services United Kingdom; ELISA L: Enzyme Linked Immunosorbent Assay; HAI: Haem Aggl utination Inhibition; CFT: Compliment fixation test; CLIA: Chemiluminescence Assay; PCR: Polymerase Chain Reacti on; RT: Real Time PCR: Polymerase Chain Reaction; BOH: Bad Obstetric History.

\section{Introduction}

The topic is debatable as field experts across the globe have different views \& opinions based on the local epidemiological data available. Bias and confusion prevail especially in developing nations about its use \& interpretation. And it is difficult to derive any international consensus; when the disease is having a varied geographical distribution or seroprevalence. Some 


\section{Annals of Immunology \& Immunotherapy}

countries have developed their own national guidelines for TROCH screening, based on the results obtained from large prospective or retrospective studies carried for good enough period of time. Here besides; clear-cut indications on when to investigate a pregnant women or neonate for TORCH infection; information on proper sample type, number and test of choice is also mentioned. Like the national guidelines from the ACOG [American college of Obstetrics and Gynaecology] HSE Ireland [Health Services Executive], FOGSI [Federation of Obstetrics and Gynaecological Societies of India] and NHS -UK [National Health Services England], for screening and management of TORCH infections in pregnancy \& in neonates [1-6]. This has been indeed helpful in prevention and control of the same. But most of the developing nations in Asia and Africa, where the seroprevalence is very high, have no guidelines in hand, or if available there is lack in adherence to it for reasons unknown. Nevertheless, hundreds of studies have been performed and published worldwide in the last three decades focusing on its significance. Majority of them being on the immune response in high-risk pregnancies and a handful on the immune response in women of child bearing age and still few on outcome of TORCH infection in symptomatic neonates. High risk group here mean pregnant women with bad obstetric history [BOH]. The utility of this data to derive any conclusions on TORCH screening is questionable for reasons mentioned below. By and large there are no multicentre studies focusing on the issue from third world countries. And met analysis of the existing data is challenging due to bias in selection of sample size, test methodology [test principle] used to determine the immune response, timing of the test and selection of right number and type of specimens, which all influences the test results and its interpretation.

From the time [1977] when NAHMIAS et al for the first time coined the acronym TORCH to describe the then four major pathogens Toxoplasma gondii, Rubella virus, Cytomegalovirus and Herpes simplex virus type 2 responsible for primary infection in pregnant women and carry the potential to cross the placenta and lead to congenital infection, growth restriction, malformations and even death of the growing foetus, the test [TORCH PANEL/ PROFILE] has been in use for screening and diagnosis of the same either appropriately or inappropriately $[7,8]$. Later the acronym was expanded to include others for ' $O$ ' in the acronym like Treponema palladium, Hepatitis B \& C virus, Human immunodeficiency virus 1 \& 2, Varicella zoster virus, Parvo virus B19 \& Enter viruses like Hepatitis E virus and Coxsackie virus depending on the endemicity of these microorganisms in the particular geographic area and its potential to cause congenital infections [8]. Therefore, some countries have syphilis, HIV $1 \& 2$ \& HBV in their panel besides the routine TORCH agents, while others have Parvo virus B19, \& Hepatitis E \& Coxsackie virus and some others have HCV, HBV \& VZV in their TORCH profile. There aren't any strict international regulations on what to be included or removed from the panel of test so far. The public health authorities need to take a serious look and arrive at conclusion so that the essence and logic behind the testing is retained.

\section{Why Troch Testing?}

Torch infection in pregnant women is asymptomatic and bears minimal effects on her health. However, in case of foetus it has significant \& deleterious effects on its viability, growth and development. It is known to cause early pregnancy loss, growth restriction, intrauterine death, still birth, congenital malformations and anomalies. Therefore, TORCH screening has a significant role to play whenever such findings are detected in exposed or symptomatic pregnant women or neonate. Vertical transmission can occur at any time during pregnancy. It may happen in the prenatal, perinatal or post-natal period. In fact, the risk of transmission of infection to the foetus is linked with the gestational age.

In case of toxoplasmosis it is known that the risk of transmission is variable from $15 \%$ at 13 weeks of gestation to $>70 \%$ at 36 weeks of gestation. But there are some reports where it is said to be significant even when the infection is acquired by the women more than 3 months before conception. There the risk of transmission of infection to the foetus is less but still possible due to persistent parasitaemia [9].

The most teratogenic among the TORCH group of agents is Rubella virus. Primary infection in mother with rubella virus carries $80 \%$ risk of transmission of infection to foetus in $1^{\text {st }}$ trimester and in $2^{\text {nd }}$ trimester the risk drops to $10-20 \%$ and at term it falls back to almost near equal to $1^{\text {st }}$ trimester levels as $60 \%$ [9].

According to the reports by organization of tetralogy information service [OTIS] The risk of CMV transmission to the foetus is $30-50 \%$ from primary infection in mother [10]. Of these babies only $10-15 \%$ shows sign and symptoms of congenital infection [10]. The overall prevalence of congenital infection is around $0.2-3 \%$ in neonates [11]. Hence majority of the infections are asymptomatic in the new born and leads to sequalae later in life. In US the prevalence of congenital CMV is 3-5 /1000 live births and 12000 - 20000 infants per year [10] and $5 \%$ of these die every year i.e. 5 in 1000 infants with 


\section{Annals of Immunology \& Immunotherapy}

congenital CMV infection [10]. As per CDC reports the risk of transmission to the foetus is $30-40 \%$ in the $1^{\text {st }}$ and $2^{\text {nd }}$ trimester of pregnancy and becomes $40-70 \%$ in the third trimester. And the risk of complications is greatest if the primary infection is acquired in $1^{\text {st }}$ trimester [12]. Around $10 \%$ of the infants born with congenital CMV will have health problems. Severe neurological infection is seen in $50-60 \%$ of congenitally infected babies. And 40-60\% born with congenital CMV disease will have long term sequelae. The risk of transmission of nonprimary CMV infection is lower as 3\%. Pregnant women who get reactivation of an old infection or are exposed to a new strain of the virus during pregnancy may have lower chances of passing the infection i.e. around $1 \%$ to the developing foetus [10].

The risk of HSV-2 transmission is $30-57 \%$ when the infection is acquired by the mother in $3^{\text {rd }}$ trimester, while it is just $1 \%$ in $1^{\text {st }}$ trimester [13]. The risk of transmission lowers around 3\% when mother is already infected and seropositive. About $85 \%$ of transmission occurs during intrapartum period [13]. Neonatal HSV is rare but serious, the prevalence rates in US is $1 / 3000$ live births $-1 / 20000$ live births annually [14].

However, irrespective of when the TORCH infection is acquired, symptoms appear variably with time in the baby. In some early and in some very late. They may be evident either at birth, in infancy or sometimes several years after the primary infection. For example, the late neurological sequelae; SNHL [sensory neural hearing loss] post congenital CMV infection is detected late in adolescence. Therefore, the key to successful management of TORCH infections lies in early diagnosis of infection by prenatal maternal screening or amniocentesis in presence of strong clinical and sonographic findings followed by timely administration of appropriate treatment plan (Table 1). In absence of which the chances of infant morbidity and mortality rises.

\section{Epidemiology and Disease Burden in Pregnant Women}

Prevalence of TORCH infections is influenced by the demographic factors like geographic location, age, gender, dietary habits, exposure to pets and socioeconomic status of the host. Several studies published so far have demonstrated their role with only few exceptions. Developing nations face the major brunt of the disease, where both the prevalence and incidence is very high. Majority of the reports are in high risk group pregnancies. Data on seroprevalence in general population is very meagre. And studies in neonates are still less. According to these studies the prevalence of acute toxoplasmosis in United Kingdom is as 1-2 /1000 pregnancies. Whereas in developing nations as per the WHO reports, the recent estimates of acute toxoplasmosis in Asia and Africa ranges between $7.7-76.7 \%$ and Nigeria stands very high with the prevalence as 76\% followed by Brazil as $50-75 \%$ [15]. In India the prevalence is reported to range between $5-58 \%$ [15]. In Middle East countries the prevalence of acute toxoplasmosis in Turkey is reported as 1.3\% and Qatar as $5.8 \%$ [16].

Rubella virus which is known to be highly teratogenic in the TORCH group of agents, has deleterious consequences on the growing foetus due to its ability to attack the dividing cells and causes defective organogenesis. Its prevalence in west is very low due to regular immunization of adolescent girls with minimum one dose and maximum two doses of the vaccine, the later dose administered usually after marriage and much before conception. Further routine antenatal screening of pregnant women for rubella is strictly adhered to. This has dramatically brought down the prevalence and incidence of the same. In developing nations; in India despite of a good rubella vaccination programme still 10 $20 \%$ of the women of child bearing age are susceptible to infection by rubella virus [15]. And as per the WHO reports, on an average annually even today more than one lakh children are born affected with congenital rubella syndrome [CRS] across the world [9]. This could possibly be due to lack of compliance to routine rubella vaccination of children or adolescent girls, especially in large parts of Africa and some countries in Asia. The overall rubella IgM seroprevalence in pregnant women in India is reported as between $4.67 \%-28.6 \%$. Moreover, it is variable with respect to different geographic locations within India, in south it is as low as 3-4.5\% and in north and west India it is as high as $26 \%$. The overall rubella immunity in Indian women of childbearing age is $71 \%$ [15].

Cytomegalovirus is ubiquitous in nature and primary infection in pregnant women is one of the leading causes of nongenetic sensorineural hearing loss and neuro developmental delay in children in west. The maternal seroprevalence varies from west to east. In west the prevalence is observed as 0.15-0.5 \% in Europe, and $0.42-1.4 \%$ in North America. In Asia and Africa, the seroprevalence is variable, in Japan it is reported as $0.5 \%$, Ivory Coast $1.38 \%$ and as Taiwan 1.8\%. CMV immunity in developing nations varies from 90- $100 \%$ [16]. The seroprevalence of acute CMV infection in India in Rajkot is as $4.7 \%$, Mumbai as $8.4 \%$, south India as $0.8 \%$ and Karnataka and Varanasi as high as of 33-35\% [15]. 


\section{Annals of Immunology \& Immunotherapy}

Acute infection with HSV -2 during pregnancy is reported in $7.6-22 \%$ of antenatal women [13-16]. In US about $22 \%$ of pregnant women have had previous exposure to HSV 2 and an additional $2 \%$ acquire the infection during pregnancy [14-16]. In India in Aligarh it is reported as $16.8 \%$, Varanasi as $33.6 \%$, Rajkot as $2 \%$ Mumbai as $3.6 \%$ and Lucknow as $3.3 \%[15,17,18]$. Around $50 \%$ of the infected women are asymptomatic and $20 \%$ of the symptomatic women transmit infection to the new born [16]. In majority of the cases neonatal infection is acquired perinatally or postnatally. Perinatally it is during the birth process by exposure to the infected birth canal. Therefore, caesarean section is always recommended as method of choice of delivery in symptomatic women with lesion in birth canal to avoid infection to the new born. Postnatal infection arises in the immediate postnatal period due to close contact between symptomatic mother and the new born.

Off late in developing nations, Parvo virus B19 has been recognized as an important cause of foetal hydrops
\& anaemia. The main route of transmission is through respiratory tract as Droplet infection. It can also spread through blood and its products and by vertical route. Growing evidence of its significance has urged most of the nations to include it in the TORCH panel. About 33-55\% of the women of child bearing age are non-immune to it. And infection rates in pregnant women vary from 1-2 \%. The risk of vertical transmission is $35 \%$. Foetal infection most commonly occurs when maternal viremia is at peak i.e. around 1-3 weeks after maternal exposure. Foetal infection manifest as intrauterine death, severe anaemia, hydrops fetalis, maternal mirror syndrome, thrombocytopenia, jaundice etc. Early diagnosis, preterm delivery with blood transfusion and symptomatic treatment is the only management plan for infected new born [9].

Table 1 Shows prevalence of TORCH Infections in women of childbearing age and pregnant women worldwide, adapted from Neu-N-TORCH-infectionsClinics-in-Perinatology 2015 [8].

\begin{tabular}{|c|c|c|c|c|}
\hline & Worldwide & $\begin{array}{c}\text { US Prevalence of Congenitally } \\
\text { Pcquired Disease in the United } \\
\text { Srevalence }\end{array}$ & \begin{tabular}{c} 
Seropositivity in Women of Childbearing Age \\
\cline { 4 - 5 }
\end{tabular} & $\begin{array}{c}\text { Sow Prevalence (\%) } \\
\text { High Prevalence (\%) }\end{array}$ \\
\hline Toxoplasmosis & $201,000^{\mathrm{b}}$ & $10-33 / 100,000$ live births & 11 (Europe) & 77 (South America) \\
\hline $\begin{array}{c}\text { Treponema } \\
\text { palladium }\end{array}$ & 36.4 million & $7.8 / 100,000$ live births & 0.67 (North America) & 10 (Central Africa) \\
\hline CMV & Unavailable & $800 / 100,000$ live broths & $30-50$ (United States) & $>90$ (South America) \\
\hline Hepatitis B & 240 million & $<0.1 / 100,000$ US population & 1.3 (North America) & $\begin{array}{c}8.7 \text { (West sub-Saharan } \\
\text { Africa) }\end{array}$ \\
\hline Hepatitis C & $130-150$ million & $<0.1 / 100,000$ US population & 1.2 (North America) & $>10$ (Middle East Asia) \\
\hline HIV & 35.3 million & 162 infants/y, 2010 & $\begin{array}{c}0.1 \text { (North America, } \\
0.2 \text { Western Europe) }\end{array}$ & 12 (Southern Africa) \\
\hline
\end{tabular}

aWomen aged $15-49$ years.

bCongenital toxoplasmosis.

Table 1: Worldwide Prevalence estimates of selected TORCH infections.

\begin{tabular}{|c|c|c|c|c|}
\hline & Toxoplasmosis & Rubella (\%) & Cytomegalovirus (\%) & HSV (\%)35 \\
\hline \multirow{2}{*}{ Europe } & \multirow{2}{*}{$19.4-43.8^{73-75}$} & \multirow{2}{*}{$96.5-97.7^{* 76-78}$} & \multirow{2}{*}{$41-69.4^{79} 80$} & HSV-I: 68.7-79.4 \\
\hline & & & & HSV-II: $5.7-21.2^{348182}$ \\
\hline \multirow{2}{*}{ Asia } & \multirow{2}{*}{$8^{83}$} & \multirow{2}{*}{$73.1-80.2^{84}$} & \multirow{2}{*}{$100^{85}$} & HSV-I: 90.3 \\
\hline & & & & HSV-II: 7.8-12.58687 \\
\hline \multirow{2}{*}{ USA } & \multirow{2}{*}{$11^{9}$} & \multirow{2}{*}{$91.5^{88}$} & \multirow{2}{*}{$70-90^{89}$} & HSV-I: 56 \\
\hline & & & & HSV-II: 173690 \\
\hline \multirow{2}{*}{ Latin America } & \multirow{2}{*}{$53^{91}$} & \multirow{2}{*}{$62^{92}$} & \multirow{2}{*}{$100^{93}$} & HSV-I: 80.7-75.8 \\
\hline & & & & HSV-II: 4-33.39495 \\
\hline \multirow{2}{*}{ Africa } & \multirow{2}{*}{$72.5-88.8^{11}$} & \multirow{2}{*}{$64.8-72.2^{9697}$} & \multirow{2}{*}{$72.2-100^{9698}$} & HSV-I: $92^{99}$ \\
\hline & & & & HSV-II: 33.2-35100 101 \\
\hline
\end{tabular}

Indicates reference from a country/continent with national vaccination programming for rubella. HSV, herpes simplex virus, IgG, immunolobulin G.

Table 2: IgG seroprevalence of women of childbearing age for TORCH. 


\section{Annals of Immunology \& Immunotherapy}

Table 2, Shows immunity to TORCH infection in women of child bearing age adapted from de jong, et al. (2013).

\section{Issues Noted with Serological Test for Torch}

Screening for TORCH infection in past by majority was considered as a single serum test. And on most of the occasions the test was advised for inappropriate indications. Problems were noted in the preanalytical and analytical phase of testing like the test request for wrong indication, and if the indication is proper, the number and type of specimen sent to the laboratory were improper. Finally, in the post analytical phase interpretation of the single serum test results was highly fallible [8].

Most of the clinicians in developing nations till today are under the false impression that TORCH screening is a single serum test [8]. As per the recommendations of FOGSI and HSE NCPP [National clinical program on pathology, Ireland] it is, a minimum of two blood samples to be tested for suspected/symptomatic TROCH infection in pregnant women or neonate. Therefore, the concept that torch test is a single serum test needs to be abandoned. And paired sera need to be examined; first sample has to collect at the time of acute infection or on the first visit in presence of strong clinical suspicion and ultra sonographic findings suggestive of infection. Second sample to be collected about 3 weeks later to see possible changes in the immune response seroconversion and rise or fall in titres] and to derive proper information from the test result. For the purpose of accurate diagnosis and timely management of the case.

Specimens that can be utilized for TROCH screening by Elisa are maternal venous blood. In new born cord blood, blood obtained by heel prick or dried blood spots. For molecular diagnosis by RT-PCR amniotic fluid by amniocentesis in foetus at 19 weeks for toxoplasma and 21 weeks for CMV especially when IgM is positive helps in confirmation. In new born, urine, nasopharyngeal swab, saliva, CSF or blood are some of the samples that can be used. These specimens can be used for isolation of the causative agent as well if facilities are available.

Next important issue in testing is proper indication for the test. It is better to refer to the national guidelines in case of doubt where clear indications for the test are mentioned. The main logic behind is to avoid un necessary investigations and undue financial burden to the patient. Testing is not required for low risk asymptomatic women. Further it is to be remembered that all women with $\mathrm{BOH}$ should not be screened for TORCH infection; as recurrent miscarriages are never caused by TORCH agents. In west where several observational studies were performed on large sample size \& type for more than 2-5 years period; sufficient enough data has been generated to derive conclusions and develop guidelines on TORCH screening. And has led the obstetricians, infectious disease specialist and foetal medicine specialist to conclude that the test needs to be individualized to the case to make it cost effective. This will improve the utility of the test. In developing countries where the prevalence is variable and highly variable within different zones of the country and with no proper reference data available, it is still being recommended to individualized the test to the target case on strong clinical suspicion and foetal sonography findings like for example the instructions provided by the FOGSI in India. Due to the fact that bad obstetric history is not always associated with TORCH infection and there are several other noninfectious causes [genetic] for bad obstetric history which needs to be considered and evaluated accordingly. Mere testing for TORCH infection is waste of time and resources and will not be fruitful. Further, majority of the patients belongs to low socioeconomic strata of the society and paired sera need to examine for accurate interpretation. Hence, affordability should not become a problem. In Indian context as per the FOGSI, 2014 guidelines screening and management of TORCH in pregnancy is recommended only when the pregnancy is complicated wi th [4].

$>$ Congenital infections in foetus like hydrops, brain lesions, unexplained IUGR, other sonographic markers of foetal infection

$>$ Pregnant women with non-vesicular rash with other sign and symptoms of systemic infection should be screened for Parvo virus B19 and rubella

$>$ Pregnant women with significant contact with a person of such illness should be investigated for Rubella and Parvo virus B 19infection irrespective of whether they develop rash or not.

\section{Diagnostic Methods}

There are several commercial screening tests available in market for TORCH infection. Immune response to TROCH agents in the form of IgM, IgA and IgG antibodies can be demonstrated in the infected host. Serological assays based on the principle of ELISA, CLIA, HAI, CFT and latex agglutination are available. HAI and CFT are only used for research purpose. Majority of the test available are based on ELISA principle and detect both IgM \& IgG responses in pregnant women. In the neonate even IgA response can be detected. While choosing ELISA as a test platform, the sensitivity and specificity of the assay needs to be assessed before advising. As this directly influences the test results and its interpretation. A highly sensitive 


\section{Annals of Immunology \& Immunotherapy}

but less specific test gives rise to high false positives results. Therefore, an IgM capture Elisa serves the purpose for being more sensitive as well as specific.

Specific diagnosis or confirmation of TORCH infection can be arrived at by isolation of the causative agent in culture or by detection and amplification of nucleic acid in the clinical specimen by PCR method.

In middle and low socioeconomic countries IgM capture ELISA is the most suitable option for diagnosis. Where the test results are equivocal, PCR can resolve the dilemma and can be recommended based on clinical judgement and patient affordability. And if PCR facility is not available; then IgG avidity assay will help in decision making to some extent.

\section{Torch Screening Protocol}

In pregnant women with history of exposure or with symptoms of TORCH infection following is the guideline for investigation:

Adapted from TORCH testing algorithms in obstetrics and neonatology HSE IRELAND. National laboratory hand book volume1.

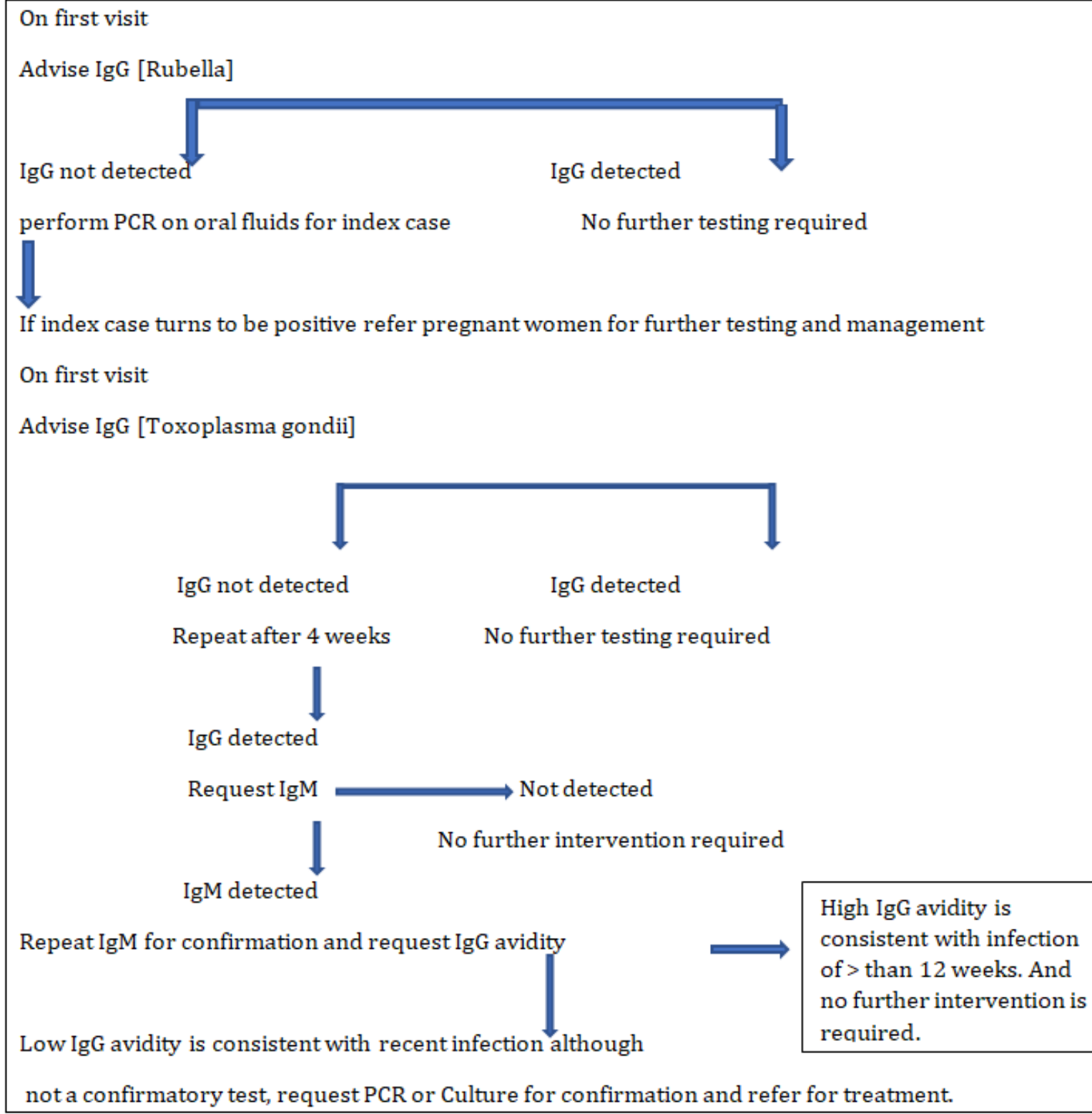




\section{Annals of Immunology \& Immunotherapy}

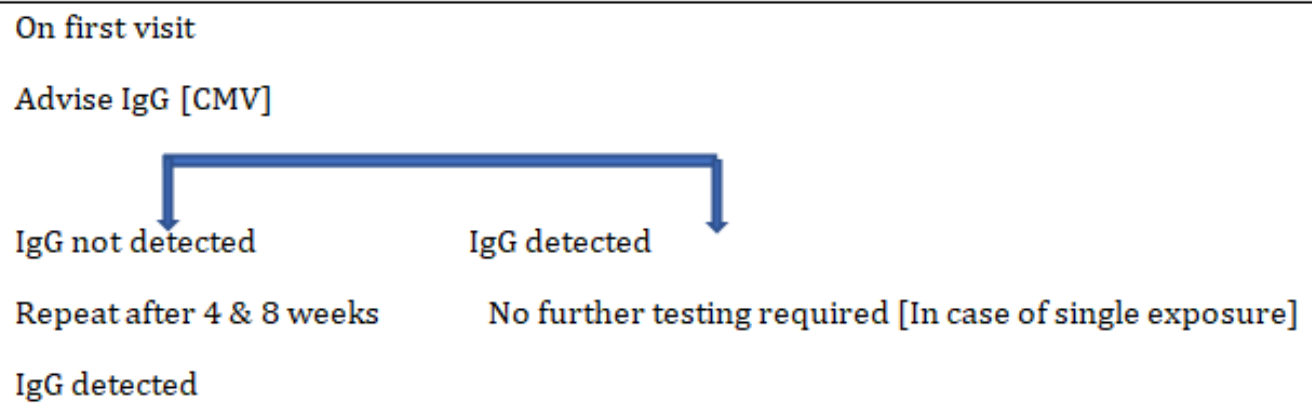

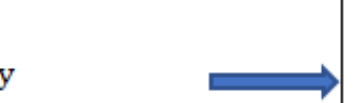

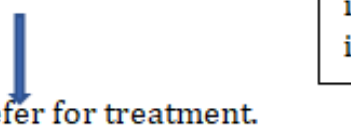

High IgG avidity is consistent with prior infection and no further intervention is required.

\footnotetext{
On first visit

Advise IgG [PARVOVIRUS B 19]

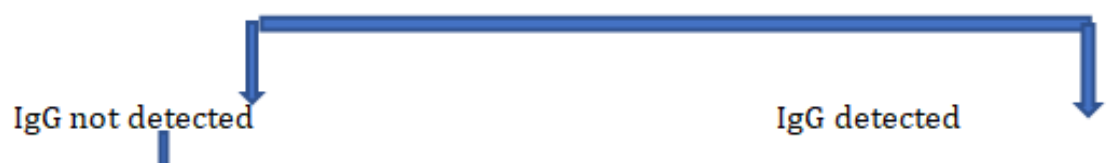

Repeat after $1-2$ week No further testing required [consider immune]

IgG detected

Request IgM $\Longrightarrow$ Not detected

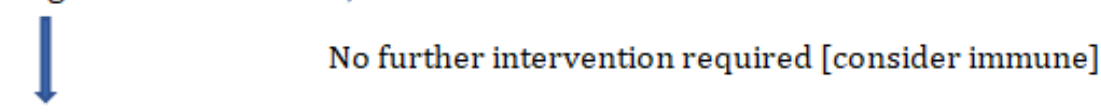

IgM detected

Request Parvovirus B19 DNA

If detected indicates recent infection treat patient accordingly

Note - If both IgM \& IgG not detected repeat test after 4 weeks to check for seroconversion.
} 


\section{Annals of Immunology \& Immunotherapy}

\section{Pregnant Women with Rash}

Vesicular rash $\Longrightarrow$ yes [varicella zoster virus infection]
No [consider Measles, Rubella, Enterovirus and Parvo virus B19]
Advise IgM for MERP
Oral fluid for Measles, Rubella IgM \& RNA
Nasal \& throat swab, stool for Enterovirus RNA \& culture.

Table 3, below shows the test of choice for suspected TORCH infections based on CNS imaging in neonates adapted from de Jong, et al. [9].

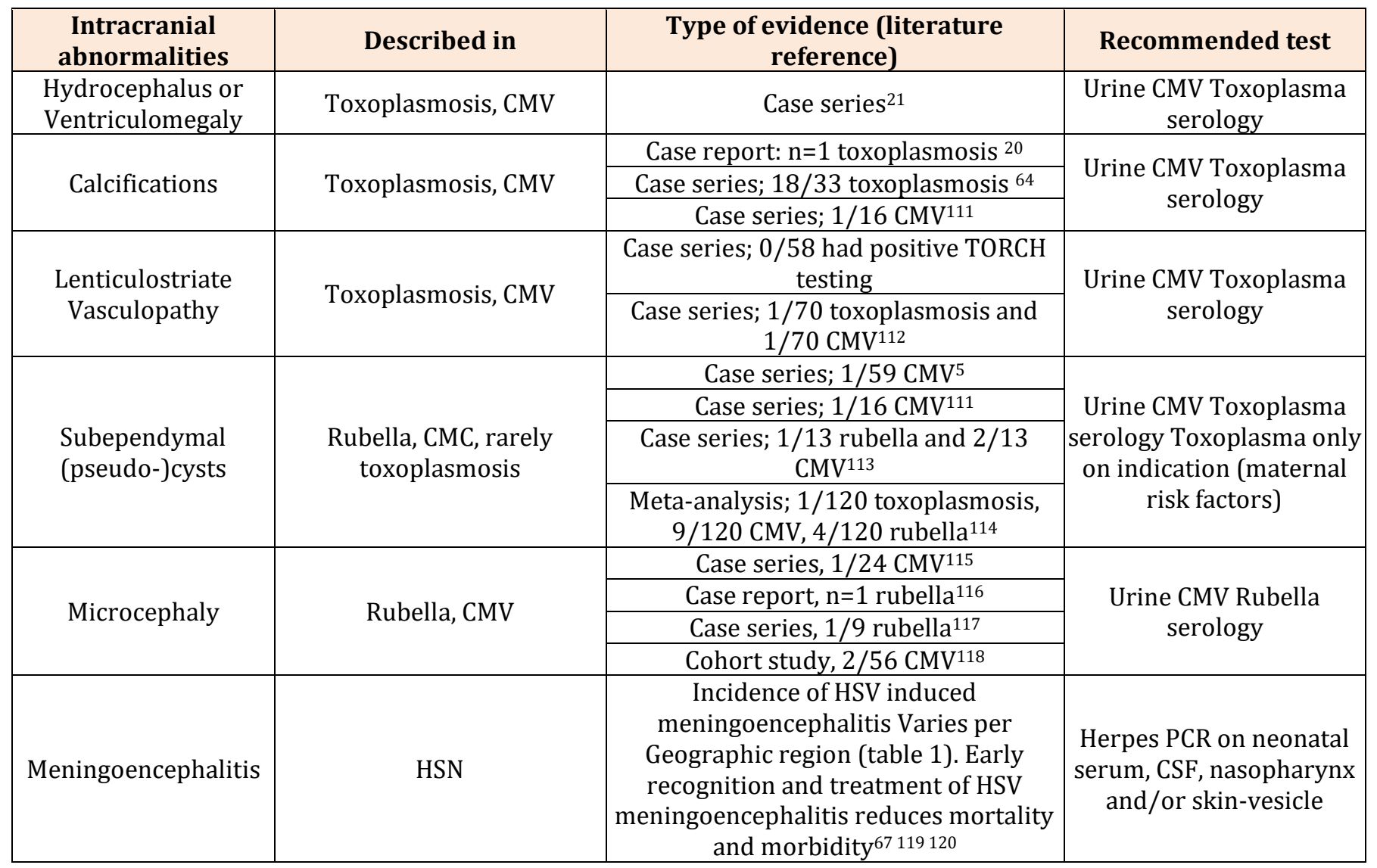

Table 3: CNS Imaging abnormalities and recommended test CMV: Cytomegalovirus; CNS: Cerebrospinal fluid; HSV: Herpes Simplex Virus. 


\section{Annals of Immunology \& Immunotherapy}

\section{Interpretation of Torch Serology}

Is very challenging and dependent on thorough knowledge about immunopathogenesis of the disease agents in the host body. Hence both the laboratory personnel and the managing clinician must have updated information on host immune response. There are 4 different scenarios in TORCH serology results.

1. Acute primary infection by TORCH group of agents as in any other infection is characterized by an $\operatorname{IgM}$ [immunoglobulin M] response, but there are several studies which have demonstrated that the acute response persists in some of the individuals for more than a year to almost 18 months. Therefore, in such situations persistent IgM response must not be confused with an acute infection. This confusion in interpretation can be avoided or resolved by examining paired sera in symptomatic individuals or screening twice in the course of the illness; initially on the first visit and later after 3 weeks of the first test. This will help to rule out acute infection or diagnose the same. In case of acute infection there will be seroconversion and increasing titres of IgG response will be seen with diminishing or absent IgM titres. In case of the neonate an IgM response always indicate an acute infection as maternal IgM antibodies never cross the placenta. Therefore, detection of IgM response in new born must be confirmed by more specific test like PCR or isolation of the causative agent by culture.

2. If IgG antibody alone is detected in a symptomatic pregnant women or neonate further testing is required.
In pregnant women IgG avidity assay is recommended which is helps in timing the infection and for follow up action. When IgG avidity test result findings are low the interpretation is clear that the infection is less than two months old and the pregnant women has to be managed as per the guidelines. In case if the IgG avidity test result findings are high then the infection is more than 4 months old and the chances of transmission of same to the foetus are remote. In symptomatic neonate if $\operatorname{IgG}$ alone is detected repeat testing is indicated to check for true foetal immune response and exclude passive maternal transfer of IgG antibodies.

3. In some of the cases where IgM result is equivocal and IgG is negative during initial testing. Caution is to be practiced while interpreting such results. This type of immune response is most often scene during seroconversion stage of acute infection and repeat testing after 3 weeks is often recommended to resolve the issue. Here on repeat test there will be either increasing or decreasing IgM response with increasing IgG values.

4. Another scenario where both the IgM and IgG are negative in the pregnant women the interpretation of the test result is simple, it means that the women is unexposed to the TORCH agents and is at a risk of acquiring infection. In case of vaccine preventable disease, it indicates she is not vaccinated. For such cases education and counselling must be provided in order to avoid infections in future and help them get immunized against rubella at least 28 days before next conception.

\begin{tabular}{|c|c|c|c|c|c|}
\hline S.no & Test Method & \begin{tabular}{|c|} 
IgM \\
Response
\end{tabular} & \begin{tabular}{|c|} 
IgG \\
Response
\end{tabular} & Interpretation & Risk of Transmission to the Foetus \\
\hline 1 & \multirow{4}{*}{$\begin{array}{l}\text { IgM Capture Elisa } \\
\text { for TORCH agents }\end{array}$} & + & 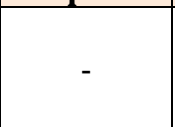 & Indicates acute infection & $\begin{array}{l}\text { Chances of transmission of infection to the } \\
\text { foetus are likely based on gestational age and } \\
\text { further testing required }\end{array}$ \\
\hline 2 & & - & - & $\begin{array}{l}\text { Unexposed / } \\
\text { non immunized }\end{array}$ & $\begin{array}{c}\text { No risk to present pregnancy. Counselling \& } \\
\text { education of woman required to get her } \\
\text { immunized against rubella and for prevention } \\
\text { of infection }\end{array}$ \\
\hline 3 & & - & + & Indicates Past infection & $\begin{array}{c}\text { Further testing required to time infection } \\
\text { with gestational age }\end{array}$ \\
\hline 4 & & Equivocal & - & \begin{tabular}{|c|} 
Early infection \\
$\begin{array}{c}\text { and check for seroconversion } \\
\text { by repeat testing }\end{array}$
\end{tabular} & Repeat testing required \\
\hline 5 & \multirow{2}{*}{$\begin{array}{c}\text { IgG avidity assay } \\
\text { for } \\
\text { Toxoplasmosis, } \\
\text { Rubella \& CMV }\end{array}$} & - & High & $\begin{array}{c}\text { Indicates infection is }>4 \\
\text { months old }\end{array}$ & $\begin{array}{c}\text { No risk to Foetus. No further testing } \\
\text { required }\end{array}$ \\
\hline 6 & & - & Low & $\begin{array}{l}\text { Indicates infection is }<2 \\
\text { months old }\end{array}$ & $\begin{array}{c}\text { Foetus at a higher risk of acquiring infection } \\
\text { correlate with foetal scans and select } \\
\text { appropriate treatment plan }\end{array}$ \\
\hline
\end{tabular}

Table 4: Summary of the TORCH test results interpretation and risk of transmission to the foetus. 


\section{Annals of Immunology \& Immunotherapy}

In case if IgG avidity test is not available and the patient is symptomatic then it is better to advise PCR or culture for detection and demonstration of the causative agent. Early detection and enumeration of viral load for CMV \& HSV -2 saves time and lives. It is found to be cost effective in neonatal herpes simplex encephalitis.

Therefore, the take home message is; TORCH screening needs to be targeted to the case and paired sera is to be examined for proper interpretation of test results. Test is of help in not only diagnosing the disease, but also timing of infection which is crucial in making clinical decisions. Interpretation of test results to be done in correlation with clinical history and sonographic findings. Specimens that can be utilized for testing in laboratory for serology are maternal venous blood, cord blood, neonatal heel prick blood or dried blood spots. For PCR amniotic fluid, urine, nasopharyngeal swabs, CSF and saliva can be used. Early and proper diagnosis helps the clinician to make appropriate clinical decision on whether to continue pregnancy with chemotherapy or justify medical termination of pregnancy [MTP] in case if severe congenital malformations are detected. But caution to be practiced as beyond 20 weeks of gestation MTP is not legalized in some countries. Here early diagnosis plays an important role.

\section{References}

1. (2015) ACOG Guidelines at a Glance: Key points about 4 perinatal infections. Obstetrics-Gynecology \& Women's Health.

2. ACOG (2015) Practice Bulletin Number 151: Cytomegalovirus, Parvovirus B19, Varicella Zoster, and Toxoplasmosis in Pregnancy. American College of Obstetricians and Gynecologists. Obstet Gynecol 125(6): 1510-1525.

3. Cilian De Gascun, Susan K TORCH testing in Obstetrics and neonataology-HSE. National clinical program in pathology. National laboratory Handbook 1: 49-59.

4. Suchitra P, Sanjay Gupta (2014) Screening and management of TORCH in pregnancy. FOGSI guidelines.

5. NHS. Screening test in pregnancy.

6. UK NHS Screening Committee about the NHS Infectious Diseases in Pregnancy Screening (IDPS) Programme.
7. Nahmias AJ, Josey WE, Naib ZM, Freeman MG, Fernandez RJ (1971) Perinatal risk associated with herpes simplex infection. Am J Obstet Gynaecol 110(6): 825-837.

8. De Jong EP, Vossen AC, Walther FJ, Lopriore E (2013) How to use... neonatal TORCH testing. Arch Dis Child Educ Pract Ed 98(3): 93-98.

9. Natallie N, Jennifer D, Philip Zachariah (2015) TORCH Infections. Clinics in Perinatology 42(1): 77-103.

10. Organization of tetralogy information specialists [OTIS 2017]: Cytomegalovirus [CMV] factsheet. Available through mother to baby.

11. Dollard SC, Grosse SD, Ross DS (2007) New estimates of the prevalence of neurological and sensory sequelae and mortality associated with congenital CMV infection. Rev Med Virol 17(5): 355-363.

12. The CMV and hearing Multicentre screening study [CHIMES] 2007-2012.

13. Straface G, Selmin A, Zanardo V, De Santis M, Ercoli A, et al. (2012) Herpes simplex virus infection in pregnancy. Infect Dis Obstet Gynecol 2012: 385697.

14. Brown ZA, Gardella C, Wald A, Marrow RA, Corey L (2005) Genital Herpes complicating pregnancy. Obstet Gynaecol 106(4): 845-856.

15. Nirmal K, Saha R, Ramachandran VG, Khan AM (2017) TORCH infection in antenatal women: A 5 year hospital based study. Eastern journal of Medical Sciences 2(4): 54-57.

16. Pradhan SV (2015) Epidemiological and serological profiles of TORCH infection in pregnancy. Journal of Pathology of Nepal 5(9): 705-708.

17. Omer Ahmed OA, Harish KB, Neena G, Ankit S, Harison M (2015) Prevalence of herpes simplex virus in pregnant women from Gangetic plain region of Allahabad, India. Advances in Microbiology 5(6): 404408.

18. Sen MR, Shukla BN, Tuhina B (2012) Prevalence of serum antibodies to TORCH infection in and around Varanasi. Northern India. J of Clin Diagn Res 6(9): 1483-1485. 